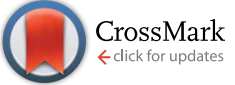

Cite this: J. Anal. At. Spectrom., 2015, 30, 2214

\title{
Sample loss in asymmetric flow field-flow fractionation coupled to inductively coupled plasma-mass spectrometry of silver nanoparticles $\uparrow$
}

\author{
Carina A. Sötebier, ${ }^{\text {*a }}$ Frank S. Bierkandt, ${ }^{a}$ Steffi Rades, ${ }^{a}$ Norbert Jakubowski, ${ }^{a}$ \\ Ulrich Panne ${ }^{\mathrm{ab}}$ and Steffen M. Weidner ${ }^{\mathrm{a}}$
}

In this work, sample losses of silver nanoparticles (Ag NPs) in asymmetrical flow field-flow fractionation (AF4) have been systematically investigated with the main focus on instrumental conditions like focusing and cross-flow parameters as well as sample concentration and buffer composition. Special attention was drawn to the AF4 membrane. For monitoring possible silver depositions on the membrane, imaging laser ablation coupled to inductively coupled plasma mass spectrometry (LA-ICP-MS) was used. Our results show that the sample residue on the membrane was below $0.6 \%$ of the total injected amount and therefore could be almost completely avoided at low sample concentrations and optimized conditions. By investigation of the AF4 flows using inductively coupled plasma mass spectrometry (ICP-MS), we found the recovery rate in the detector flow under optimized conditions to be nearly $90 \%$, while the cross-flow, slot-outlet flow and purge flow showed negligible amounts of under $0.5 \%$. The analysis of an aqueous ionic $\mathrm{Ag}$ standard solution resulted in recovery rates of over $6 \%$ and the ionic $\mathrm{Ag}$ content in the sample was found to be nearly $8 \%$. Therefore, we were able to indicate the ionic Ag content as the most important source of sample loss in this study.

Received 22nd July 2015

Accepted 12th August 2015

DOI: $10.1039 / c 5 j a 00297 d$

www.rsc.org/jaas and $100 \mathrm{~nm}$ in at least one dimension. Since this definition is already applied in the EU cosmetic product regulation, which states that cosmetic products containing NMs must be notified to a commission, the analysis of NMs is still crucial.

A variety of instrumentation is currently used for the size determination of NPs and compared in different reviews. ${ }^{12-14}$ Many of these techniques are not applicable when investigating samples with a complex matrix, mixtures in terms of size and elemental composition, particles having a broad size distribution or low NP concentrations. Dynamic light scattering (DLS), for example, can only be applied to determine narrow distributed or monodisperse particle systems with higher concentration. $^{14}$ Other techniques, such as transmission electron microscopy (TEM) or secondary electron microscopy (SEM), might be hampered by particle agglomeration or aggregation during the sample preparation procedure. ${ }^{15} \mathrm{X}$-ray techniques, for instance small angle X-ray scattering (SAXS), are limited to particles smaller than $50 \mathrm{~nm}$ in diameter. ${ }^{16}$ A simple and fast way for the characterization of particles with a diameter greater than approximately $20 \mathrm{~nm}$ is inductively coupled plasma mass spectrometry (ICP-MS) in the single particle detection mode. ${ }^{17,18}$

The use of hyphenated techniques, such as separation techniques coupled to elemental detectors, is growing due to their ability to obtain simultaneously particle size and multielemental information. Separation techniques include size exclusion chromatography (SEC), hydrodynamic chromatography (HDC), and field-flow fractionation (FFF). Whereas SEC

11, 12489 Berlin, Germany. E-mail: carina.soetebier@bam.de

${ }^{b}$ Humboldt-Universität zu Berlin, Department of Chemistry, Brook-Taylor-Str. 2, 12489 Berlin, Germany

$\dagger$ Electronic supplementary information (ESI) available. See DOI: 10.1039/c5ja00297d 
has a limited size separation range, HDC has the lowest separation power of these three techniques but can also be used to detect the ionic fraction. In this work, size separation was performed using asymmetrical flow field-flow fractionation (AF4). AF4 is frequently applied for the separation of nanoparticles due to its high separation power, broad size separation range from 1 to $1000 \mathrm{~nm}$ (Brownian mode) and its ability to remove matrix constituents to a certain extent. ${ }^{12,19}$ Thus, for a simultaneous size characterization and quantification of the Ag NPs in suspension, the hyphenation of AF4 and ICP-MS is a promising tool. However, optimizing the separation conditions in order to achieve high recovery rates and resolution is still a challenge in AF4. Poor recovery rates for Ag NPs have been reported previously. ${ }^{19-23}$ Most of the reported recovery rates have been calculated by a comparison of common AF4 analyses with experiments performed without channel cross-flow, neglecting possible system losses. ${ }^{\mathbf{1 9 2 4 - 2 7}}$ Several studies investigated different parameters influencing the recovery rates. Their results demonstrate that the choice of the membrane (material and pore size) and eluent (ionic strength, $\mathrm{pH}$, salt content, surfactant), as well as instrumental parameters, such as the injection and focusing time and the focus flow strength, have a great effect on both the resolution and recovery rates. ${ }^{23,24}$ Bendixen $e$ a $a .^{28}$ showed that the zeta potential, which depends on the choice of the membrane and the eluent, has a significant impact on the recovery rate. However, this could not completely explain the observed sample loss of up to $75 \%$. Sample loss is generally reported to occur on the membrane surface, ${ }^{20,24,29}$ by cross-flow ${ }^{24}$ or by aggregation. ${ }^{25}$ Other authors reported that the membrane must be conditioned before the measurements by several injections of a concentrated Ag NP suspension to achieve constant recovery values with low standard deviations. ${ }^{\mathbf{2 6 , 3 0}}$ Depending on the number of injected samples, an increase in the detector signal could be found. ${ }^{29}$ By comparing different membrane materials and pore sizes these authors also investigated unspecific membrane-particle interactions resulting in poor resolution and low recovery rates.

Neither a reasonable proof for $\mathrm{Ag}$ residues on the membrane nor an estimation of its relevance to the recovery rates has been published so far. The aim of this work was to examine sample loss and recovery rates in the AF4-ICP-MS hyphenation. Thus, systematic investigations of the sample loss in the system, e.g. through the cross-flow and/or by deposition on the membrane, have been performed. To determine the amount and the location of the $\mathrm{Ag}$ residue on the membrane imaging laser ablationICP-MS (LA-ICP-MS) has been utilized. A reference material (CRM) certified by SAXS was chosen for this study.

\section{Experimental}

\section{Materials}

Ultrapure water $\left(18.2 \Omega \mathrm{cm}^{-1}\right)$ was generated by a Millipore Element system (EMD Millipore, Billerica, MA, USA) equipped with a Quantum ICP Polishing Cartridge. CertiPUR grade Ag, indium (In) and lanthanum (La) elemental standards and nitric acid (p.A., 65\%) were purchased from Merck (Darmstadt, Germany). The nitric acid was subboiled prior to use. As a NP sample the in-house certified reference material BAM N-001 (BAM, Berlin, Germany) with certified particle size values of $d_{10}=12.0 \pm 1: 9 ; d_{50}=18.5 \pm 2.5$ and $d_{90}=34.6 \pm 4.8 \mathrm{~nm}$ (volume weighted diameter) and $d_{10}=6.9 \pm 2.7, d_{50}=12.6 \pm 2.1$ and $d_{90}=19.4 \pm 2.2 \mathrm{~nm}$ (number weighted diameter) was used. The Ag NPs were suspended in a $0.94 \mathrm{mM}$ ammonium nitrate solution and stabilized both sterically and electrostatically with Tween-20 and Tagat TO. ${ }^{31}$ Before analysis and dilution, the samples were thoroughly shaken for $5 \mathrm{~min}$. To avoid aggregation or oxidation of the Ag NPs, diluted samples were stored in the dark at $4{ }^{\circ} \mathrm{C}$ and were allowed to equilibrate to ambient temperature for $5 \mathrm{~min}$ prior to the analysis. Polystyrene particles (Postnova Analytics, Landsberg am Lech, Germany) with mean diameters of $20 \pm 2,46 \pm 2$ and $102 \pm 3 \mathrm{~nm}$ were used for the calibration of AF4. For LA-ICP-MS calibration the standard reference material NIST SRM612 (NIST, Gaithersburg, MD, USA) was used.

\section{Instruments}

Asymmetrical flow field-flow fractionation. An AF4 apparatus (AF2000, Postnova Analytics, Landsberg am Lech, Germany) equipped with a $280 \mathrm{~mm}$ channel, a $5 \mathrm{kDa}$ PES membrane and a $350 \mu \mathrm{m}$ spacer (all from Postnova Analytics, Landsberg am Lech, Germany) was used for NP separation. The slot-outlet flow used during the experiments was manually regulated by capillaries. For off-line AF4-ICP-MS experiments ultrapure water containing $200 \mathrm{mg} \mathrm{L}^{-1} \mathrm{NaN}_{3}$ and for on-line AF4-ICP-MS experiments ultrapure water were used as eluents. The eluents were filtered (0.1 $\mu \mathrm{m}$ mixed cellulose ester filter, Whatman GmbH, Dassel, Germany) prior to use. Two different gradients were applied for the separation. For the size calibration using polystyrene particles an injection time of $10 \mathrm{~min}$, a transition time of

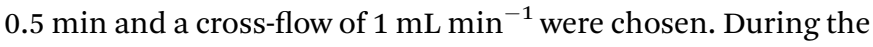
analysis time of 10.5 to $30.5 \mathrm{~min}$, the cross-flow was reduced to $0 \mathrm{~mL} \mathrm{~min}^{-1}$ and kept at constant for another $10 \mathrm{~min}$. A gradient with an injection time of $5 \mathrm{~min}$ and a transition time of $0.5 \mathrm{~min}$ using a higher cross-flow of $2 \mathrm{~mL} \mathrm{~min}^{-1}$ was chosen in order to achieve a higher resolution and separation of a main and a shoulder peak. Between the analysis time of 23.5 and $33.5 \mathrm{~min}$, the cross-flow was reduced to $0 \mathrm{~mL} \mathrm{~min}^{-1}$ and kept constant for additional $25 \mathrm{~min}$. UV/Vis detection was performed using a Shimadzu SPD-20M diode array detector (DAD) (Kyoto, Japan). The wavelengths 254 (polystyrene standards and Tween 20/Tagat TO coating) and $430 \mathrm{~nm}$ (Ag NPs) were chosen for detection.

DLS and zeta potential. DLS and zeta potential experiments were performed using a Zetasizer Nano ZS (Malvern Instruments Ltd, Malvern, UK). The Ag NP suspension was diluted $1: 10$ with the eluent and filtered through a $0.2 \mu \mathrm{m}$ PES syringe filter (Carl Roth GmbH + Co. KG, Karlsruhe, Germany) before the analysis. The data are intensity weighted. The $\mathrm{pH}$ values were determined using $\mathrm{pH}$-indicator paper (Lyphan, Neuhaus am Rennweg, Germany).

ICP-MS. The total silver concentration of the Ag NPs was determined using an XSeries II instrument (Thermo Fisher Scientific, Waltham, MA, USA). The ionic silver concentration analyses and AF4-ICP-MS hyphenations were performed under 
the use of an iCAP Q ICP-MS instrument (Thermo Fisher Scientific, Waltham, MA, USA). The experimental conditions are compiled in Table 1.

Laser ablation ICP-MS. Experiments were performed using a LSX-213 Nd:YAG laser system (Cetac, Omaha, NE, USA) coupled to an XSeries II ICP-MS (Thermo Fischer Scientific, Waltham, MA, USA). The ablation cell is a prototype design which has a second gas inlet opposite to the primary inlet described elsewhere. ${ }^{32}$ Before the analysis, the system was tuned by ablating line scans with $200 \mu \mathrm{m}$ spot size, $10 \mu \mathrm{m} \mathrm{s}^{-1}$ scan rate, $20 \mathrm{~Hz}$ repetition rate and $100 \%$ laser energy of a standard glass (NIST SRM612).

For our experiments, the membranes were cut, fixed on microscopic glass slides (Thermo Fisher Scientific, Waltham, MA, USA), and mounted in the ablation cell, which can be moved in the $x y z$-direction relative to the laser beam. The samples were ablated with $20 \mathrm{~Hz}$ and a scan rate of $100 \mu \mathrm{m} \mathrm{s}^{-1}$ at a laser energy of 1.2-2 mJ. The spot size was $200 \mu \mathrm{m}$ and the irradiance $7.6-12.7 \mathrm{GW} \mathrm{cm}^{-2}$. To reduce the ablation time, a complete membrane was ablated in parallel lanes with a distance of 1-3 mm. To image and quantify the residue, the first part of the membrane was completely ablated in parallel, adjacent line scans with a lane distance of $175 \mu \mathrm{m}$. The formed aerosol was transported by a He carrier gas flow from the cell to the ICP-MS, where an additional Ar gas flow was introduced prior to the atomization and ionization in the plasma. Since the analyzed membrane areas were too large to be ablated in one session, each membrane was ablated in consecutive sessions. Blank and background correction were performed for the quantification experiments. A dried droplet calibration was used for quantification (see the section 'Sample preparation'). The detected ICP-MS line scans were merged to a contour plot.

The used conditions were tested on the membrane before analysis to assure the complete coverage of the surface. Under

Table 1 ICP-MS parameters

\begin{tabular}{|c|c|c|c|}
\hline Parameter & AF4-ICP-MS & LA-ICP-MS & $\begin{array}{l}\text { Total Ag } \\
\text { concentration } \\
\text { determination }\end{array}$ \\
\hline ICP-MS & iCAP Q & XSeries II & XSeries II \\
\hline Power/W & 1550 & 1400 & 1400 \\
\hline $\begin{array}{l}\text { Nebulizer/additional } \\
\text { gas (LA-ICP-MS) } \\
\text { flow rate/L } \mathrm{min}^{-1}\end{array}$ & $1.04-1.07$ & 0.48 & 0.98 \\
\hline $\begin{array}{l}\text { Carrier gas } \\
(\mathrm{He}) / \mathrm{L} \mathrm{min}^{-1}\end{array}$ & - & 0.9 & - \\
\hline $\begin{array}{l}\text { Aux. gas flow } \\
\text { rate/L } \mathrm{min}^{-1}\end{array}$ & 0.8 & 0.7 & 0.7 \\
\hline $\begin{array}{l}\text { Cool gas flow } \\
\text { rate/L } \min ^{-1}\end{array}$ & 14 & 13 & 13 \\
\hline Dwell time/ms & $a$ & 50 & 100 \\
\hline Isotopes monitored & $\begin{array}{l}{ }^{107} \mathrm{Ag},{ }^{109} \mathrm{Ag},{ }^{115} \mathrm{In} \\
\left(\text { or }{ }^{139} \mathrm{La}\right)^{b}\end{array}$ & ${ }^{107} \mathrm{Ag},{ }^{109} \mathrm{Ag}$ & $\begin{array}{l}{ }^{107} \mathrm{Ag},{ }^{109} \mathrm{Ag}, \\
{ }^{115} \mathrm{In},{ }^{139} \mathrm{La}\end{array}$ \\
\hline
\end{tabular}

${ }^{a}$ Dwell times were chosen as follows: off-line AF4-ICP-MS $10 \mathrm{~ms}$, on-line AF4-ICP-MS $200 \mathrm{~ms}$, flow injection and experiments without cross-flow $10 \mathrm{~ms}\left({ }^{107} \mathrm{Ag},{ }^{109} \mathrm{Ag}\right)$ and $200 \mathrm{~ms}\left({ }^{115} \mathrm{In}\right) .{ }^{b}$ Used during off-line AF4-ICPMS experiments. the applied laser parameters the membranes, which consist of two layers, were not completely ablated but only the cellulose bottom layer remained. Ablation of the polymer top layer led to deposition of a black residue on the inside of the ablation cell glass. To prevent absorption of the laser by this residue and thus the impairment of the membrane ablation, regular cleaning was necessary.

\section{Sample preparation}

Determination of the total Ag concentration. A sample preparation published in previous studies, based on the decomposition of the particles in half concentrated nitric acid, was applied. ${ }^{33}$ In contrast to this method, In was used as the internal standard. The calibration was performed in the same manner as that for the samples. A sample concentration of approximately $6 \mu \mathrm{g} \mathrm{\textrm {L } ^ { - 1 }} \mathrm{Ag}$ was chosen. Each calibration point and the blank were prepared in three and the sample in twelve replicates.

Determination of the ionic Ag concentration. A procedure similar to a previously published method was applied. ${ }^{33}$ Three polyethersulfone (PES) $10 \mathrm{kDa}$ ultrafiltration units (Roti spin Midi-10, Carl Roth GmbH + Co. KG, Karlsruhe, Germany) were conditioned by rinsing with ultrapure water. The units were filled twice with $3.5 \mathrm{~mL}$ ultrapure water and centrifuged (Heraeus Biofuge primo R, Kendro Laboratory Products $\mathrm{GmbH}$, Hanau, Germany) at $2676 \mathrm{~g}$ for $60 \mathrm{~min}$. A volume of $100 \mu \mathrm{L}$ undiluted NP suspension was added onto the membrane and centrifuged at $2676 \mathrm{~g}$ for $15 \mathrm{~min}$. Membrane washing was performed by adding $300 \mu \mathrm{L}$ of ultrapure water onto the membrane and centrifuging again for $15 \mathrm{~min}$. The washing step was performed three times. To an aliquot of $150 \mu \mathrm{L}$ of the filtered solution, La was added as an internal standard. The sample was further diluted 1 : 100 in $2 \%$ nitric acid to a final concentration of $10 \mu \mathrm{g} \mathrm{L}^{-1} \mathrm{La}$. An aqueous $\mathrm{Ag}$ standard solution was used for calibration.

Off-line AF4-UV/Vis-ICP-MS experiments. A volume of $100 \mu \mathrm{L}$ of the undiluted $\mathrm{Ag}$ NPs with a concentration of $62.52 \pm 1.21$ $\mathrm{mg} \mathrm{L}^{-1}$ was injected into the system. The size determination via AF4-UV/Vis was performed by applying an AF4 focus time of $10 \mathrm{~min}$, whereas a reduced focus time of $5 \mathrm{~min}$ was used for the ICP-MS experiments. In order to reduce the detector flow and to increase the sample concentration as well as the resolution, the slot-outlet technique was used. ${ }^{34}$ For these experiments a detector flow of $1 \mathrm{~mL} \min ^{-1}$ with a slot-outlet flow of $79 \%$ was used.

For fraction collection (90 s intervals) a collector (Gilson 221 XL, Gilson Inc., Middleton, WI, USA) was chosen. The fractions were acidified with 5\% nitric acid and diluted with ultrapure water. An aqueous La standard solution was added for drift correction. Analysis was performed using ICP-MS. For the calibration of the $\mathrm{Ag}$ concentration, an aqueous $\mathrm{Ag}$ standard solution was used.

On-line AF4-ICP-MS. Two concentrations of the Ag NPs were investigated, a low concentration with $0.25 \mathrm{mg} \mathrm{L}^{-1}$ (membrane 1) and a higher concentration with $3.13 \mathrm{mg} \mathrm{L}^{-1} \mathrm{Ag}$ (membrane 2). An injection volume of $10 \mu \mathrm{L}$ with a focus time of $3 \mathrm{~min}$, a detector flow of $1 \mathrm{~mL} \mathrm{~min}^{-1}$ and a slot outlet flow of $60 \%$ were chosen. Ultrapure water was used as the eluent. An aqueous In standard 
solution dissolved in 5\% nitric acid was added post-channel as a drift correction standard. On-line quantification was performed by flow injection of an aqueous Ag standard solution during the AF4 focusing time in triplicates. The limit of detection (LOD) was given by a signal to noise ratio of $3: 1$. A five point adjacent average smoothing of the on-line AF4-ICP-MS fractograms was performed using OriginLab software (OriginLab Corporation, Northampton, MA, USA).

To determine possible regions of sample loss, experiments without cross-flow were performed. In an additional experiment, the manual injection valve was directly connected to the T-piece, where the internal standard was added, thus bridging the AF4 channel. Six replicates have been analyzed for each of the two methods.

LA-ICP-MS. Each of the $5 \mathrm{kDa}$ PES membranes was leached with $20 \%$ methanol overnight and thoroughly equilibrated with the eluent. For the quantification, a matrix-matched dried droplet calibration was performed. This method consisted of seven different concentrations of the Ag NPs and a blank, which were placed in $0.5 \mu \mathrm{L}$ droplets on the membrane. After drying, these droplets were ablated completely.

For imaging experiments, a membrane onto which Ag NPs with an absolute Ag mass of $25.0 \mu \mathrm{g}$ had been injected over four off-line AF4-ICP-MS runs was dried. As the AF4 eluent ultrapure water containing $200 \mathrm{mg} \mathrm{L}^{-1} \mathrm{NaN}_{3}$ was used. The membrane was cut into three smaller pieces.

For the quantification, one blank and two sample membranes were prepared. For the blank membrane $10 \mu \mathrm{L}$ of ultrapure water and for the sample membranes $10 \mu \mathrm{L}$ of Ag NPs with concentrations of $0.25 \mathrm{mg} \mathrm{L}^{-1}$ (membrane 1) and 3.13 $\mathrm{mg} \mathrm{L}^{-1} \mathrm{Ag}$ (membrane 2) were injected per run. Ultrapure water was used as the eluent. After ten runs, the membrane was removed from the channel and dried. The first part of the membrane, which showed the highest $\mathrm{Ag}$ content in the imaging experiment, was fully ablated. A length of approximately $55 \mathrm{~mm}$ from the sample introduction point was chosen. All ICP-MS conditions are compiled in Table 1.

\section{Results and discussion}

\section{Size determination using AF4-UV/Vis}

Before the AF4-UV/Vis analyses, the zeta potential of the Ag NPs was determined in a 10-fold dilution in ultrapure water with 200 $\mathrm{mg} \mathrm{L}^{-1} \mathrm{NaN}_{3}$ to investigate their stability during the AF4 analysis. A frequently observed behavior in our laboratory was the aggregation of Ag NPs during the experiment due to insufficient stabilization. The obtained zeta potential value of $-28.33 \pm$
$2.7 \mathrm{mV}$ for ultrapure water with $200 \mathrm{mg} \mathrm{L}^{-1} \mathrm{NaN}_{3}$, shown in Table 2, is considered slightly stable with only few aggregates, whereas ultrapure water gives a zeta potential of $-18.0 \pm 1.3 \mathrm{mV}$ indicating potential agglomerates. ${ }^{35}$

The AF4 fractogram in Fig. 1 of the Ag NPs using UV/Vis detection showed a single peak with a retention time of $17.8 \pm$ $0.1 \mathrm{~min}$. The size determination should ideally be performed with reference materials of a known size and the same elemental composition. There is only one size-certified Ag NP reference material currently available in the market. This material is regarded as a sample in this work as reliable AF4 data are still lacking. For statistically firm results, a calibration curve must contain at least three standards. Therefore, the calibration of the hydrodynamic diameter was performed using polystyrene particle standards, which had been proven to be suitable calibration standards for AF4 analyses in previous studies. ${ }^{28,36}$ However, under the used conditions a non-optimal behavior was detected as an exponential calibration curve was obtained as shown in Fig. 1. A possible reason might be a repulsion of the larger particles and the membrane. As calibration standards with a Tween-20 and Tagat TO coating, which has the same AF4 behavior as the sample, are lacking, the size determination performed in this work was considered to be an estimation. Retention times for the polystyrene standards were $13.9 \pm 0.4,21.5 \pm 0.5$ and $27.8 \pm 0.3 \mathrm{~min}$ for the 20,46 and 102 $\mathrm{nm}$ particles, respectively.

Applying the calibration shown in Fig. 1, a hydrodynamic size of $28.82 \pm 0.21 \mathrm{~nm}$ was calculated for the Ag NPs at their peak maximum. Fig. 1 shows a slight peak shoulder. According to the certified SAXS values, Ag core diameters of $d_{10}=12.0 \pm$ $1: 9 ; d_{50}=18.5 \pm 2.5$ and $d_{90}=34.6 \pm 4.8 \mathrm{~nm}$ (volume weighted) were determined indicating a distribution with a tailing to larger particle sizes. Using dynamic light scattering a diameter of $49.51 \pm 1.95 \mathrm{~nm}$ was obtained (see Table 2). Since larger particles scatter light with a higher intensity, their influence on the resulting diameter is much higher than that of smaller ones. This finding is in good agreement with data displayed in Fig. 1. Scanning electron microscopy measurements in transmission mode (T-SEM) resulted in a particle diameter of $15 \pm 5 \mathrm{~nm}$ (number weighted), which is in good agreement with the certified SAXS values of $d_{10}=6.9 \pm 2.7, d_{50}=12.6 \pm 2.1$ and $d_{90}=19.4 \pm 2.2 \mathrm{~nm}$ (number weighted). A T-SEM image, illustrating a presumably at least bimodal distribution, can be found in Fig. S1 in the ESI. $\dagger$ To determine whether the NPs showed a large polydispersity or a bimodal distribution, a gradient with a higher cross-flow and a longer linear cross-flow region was applied. The result in Fig. 2 clearly depicts a higher

Table 2 Zeta potential and hydrodynamic diameter of Ag NPs for off-line and on-line AF4-ICP-MS conditions

\begin{tabular}{|c|c|c|c|c|c|c|}
\hline Hyphenation & Eluent & Zeta potential/mV & Conductivity $/ \mathrm{mS} \mathrm{cm}^{-1}$ & $\mathrm{pH}$ & $\begin{array}{l}\text { Hydrodynamic diameter } \\
\text { (DLS)/nm }\end{array}$ & $\begin{array}{l}\text { Peak width } \\
\text { (DLS)/nm }\end{array}$ \\
\hline Off-line & $\begin{array}{l}\text { Ultrapure water with } \\
200 \mathrm{mg} \mathrm{L}^{-1} \mathrm{NaN}_{3}\end{array}$ & $-28.3 \pm 2.7$ & $0.319 \pm 0.006$ & 7 & $49.5 \pm 2.0$ & $26.7 \pm 5.9$ \\
\hline On-line & Ultrapure water & $-18.0 \pm 1.3$ & $0.023 \pm 0.003$ & 7 & $51.1 \pm 2.1$ & $30.4 \pm 6.2$ \\
\hline
\end{tabular}




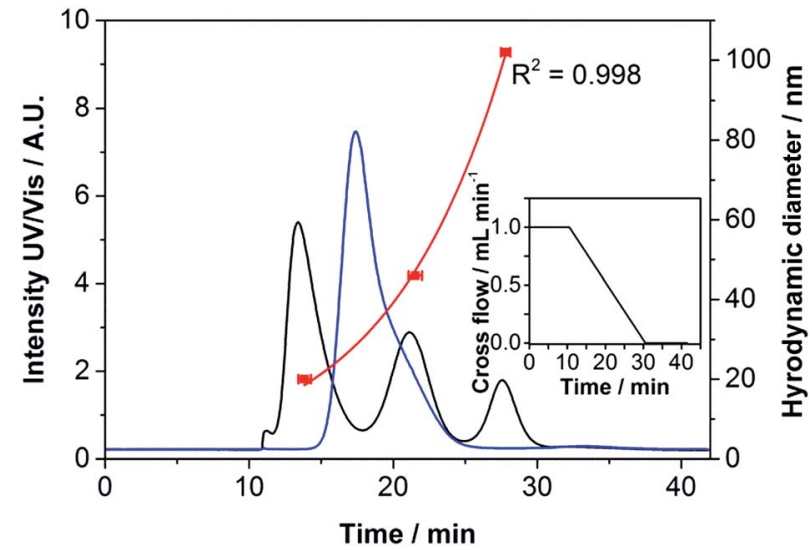

Fig. 1 UV/Vis fractogram of the Ag NPs (blue line, $\lambda=430 \mathrm{~nm}$ ) calibrated with three polystyrene standards (black line, $\lambda=254 \mathrm{~nm}$ ). The resulting calibration curve (red line) and used cross-flow profile (black line, small graph) are given. The absolute injected mass was $6.3 \mu \mathrm{g} \mathrm{Ag}$.

peak resolution. As the peak shoulder already shown in Fig. 1 can be further separated from the main peak, Fig. 2 supports the assumption of an at least bimodal distribution. A good agreement between the UV/Vis and ICP-MS fractograms was obtained.

\section{Off-line AF4-ICP-MS experiments}

The determination of the total $\mathrm{Ag}$ concentration in the $\mathrm{Ag} \mathrm{NP}$ sample using acid digestion followed by ICP-MS analysis resulted in a concentration of $62.5 \pm 1.2 \mathrm{mg} \mathrm{L}^{-1}$. Based on this value, the recovery rate of the off-line AF4-ICP-MS analysis (see Fig. 2) was $40.7 \pm 0.4 \%$.

A potential sample loss could be expected on the walls of the vials used for the fraction collection as well as through the cross-flow. Therefore, the complete detector flow was collected in a batch. Additionally, the $\mathrm{Ag}$ concentration in the cross-flow,

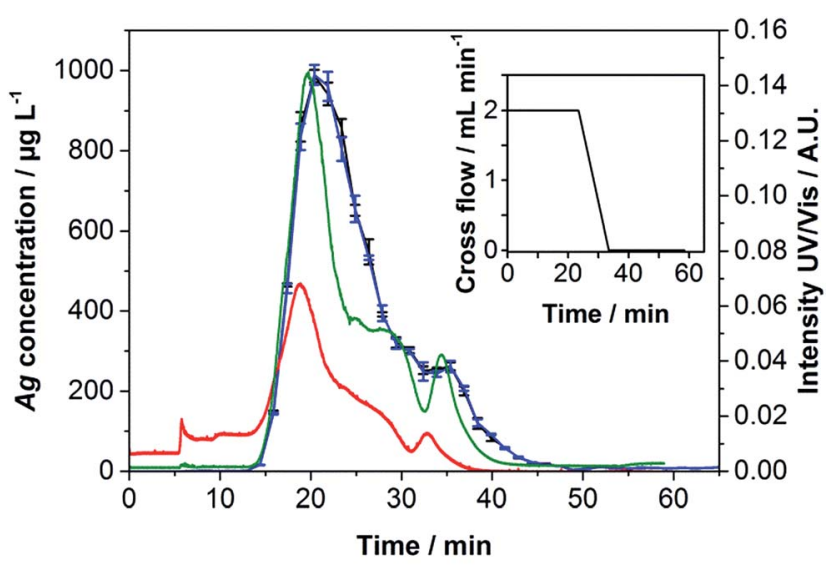

Fig. 2 Fractogram of Ag NPs using the modified cross-flow gradient (black line, small graph). Fractions for ICP-MS experiments were collected in intervals of $90 \mathrm{~s}$. Black and blue lines - amount of ${ }^{107} \mathrm{Ag}$ and ${ }^{109} \mathrm{Ag}$, red and green lines - UV/Vis intensities at 254 and $430 \mathrm{~nm}$. The absolute injected mass was $6.3 \mu \mathrm{g} \mathrm{Ag}$. slot-outlet flow and purge flow was determined. In Table 3, the concentrations and recovery rates of all analyzed flows are given. A scheme visualizing the different AF4 flows can be found in the ESI (Fig. S2 $\dagger$ ).

These results show that the sample losses through the crossflow, slot-outlet flow and purge flow were negligible compared to the value of the detector flow and the total $\mathrm{Ag}$ concentration of the Ag NPs. An increased recovery rate compared to the fractionation experiment was also found. A possible explanation could be the drastic reduction of vial surface area.

\section{Investigation of sample loss on the membrane}

Since separation in the AF4 is based on a channel that is equipped with a membrane, another possible reason for the sample loss could be the adsorption of Ag NPs on the membrane. A 5 kDa PES membrane, which has been used for four off-line AF4-ICP-MS runs with a total injection mass of $25.0 \mu \mathrm{g} \mathrm{Ag}$, was analyzed by LA-ICP-MS. This technique also allows the localization of the $\mathrm{Ag}$ residue.

The scan in Fig. 3 shows that $\mathrm{Ag}$ was found on the membrane. The highest Ag intensities were detected close to the injection point (A). High intensities were also found at the focusing point (B) and on the channel edge.

In order to avoid the sample residue on the membrane, several parameters were optimized. The sample concentration, for example, plays an important role in terms of overloading effects $^{37}$ and a too long focusing time can cause losses of low molecular weight material. ${ }^{38}$ Experiments performed in our laboratory varying the focusing time and the sample load did not result in an increase of the recovery rate or have an influence on the fractogram (results not shown here). Therefore overloading effects can be excluded. On-line AF4-ICP-MS hyphenation was chosen to prevent potential sample loss on vial surfaces and drastically reduce the analysis time. For the on-line experiments, a reduction of the total injected Ag mass was necessary. Therefore, a shorter focus time was chosen. As the interaction of the sample with the membrane is proposed to be significantly based on the zeta potential, ${ }^{28,29}$ only ultrapure water was used as an eluent during the on-line measurements. Changes to the zeta potential were noticed as shown in Table 2 .

\section{On-line AF4-ICP-MS experiments}

The obtained fractograms (Fig. 4) were similar to those of the off-line experiments. Only very few aggregates were detected, in spite of the higher zeta potential shown in Table 2. Bendixen et al. have already investigated the influence of the zeta

Table 3 Detected $\mathrm{Ag}$ amounts and recovery rates for the batch collection of the four AF4 flows

\begin{tabular}{lcl}
\hline Flow & Ag amount/ng & Recovery rate/\% \\
\hline Detector flow & $3478.98 \pm 51.49$ & $55.65 \pm 0.82$ \\
Cross-flow & $0.75 \pm 0.01$ & $0.012 \pm 0.001$ \\
Slot-outlet flow & $28.85 \pm 0.29$ & $0.462 \pm 0.005$ \\
Purge flow & $1.55 \pm 0.10$ & $0.025 \pm 0.002$
\end{tabular}



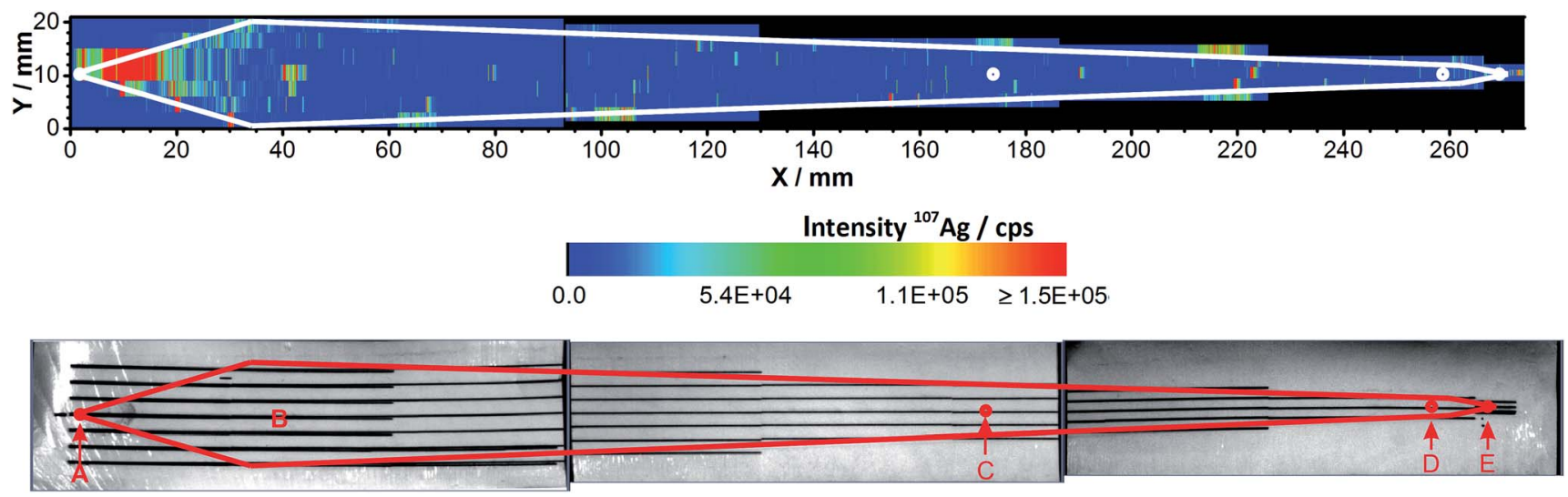

Fig. 3 LA-ICP-MS contour plot of ${ }^{107} \mathrm{Ag}$ (top) and photograph (bottom) of the completely ablated membrane, both with a marked channel profile. Areas not ablated are depicted in black (top). Small dots represent (A) tip flow inlet and sample injection point, (B) focusing point, (C) focus flow inlet, (D) slot-outlet and (E) detector flow outlet.

potential on both the membrane and the particles and shown its importance. ${ }^{28}$ Literature states that a more negative zeta potential achieves a better stabilization of the NPs. ${ }^{35}$ However, the results obtained in this work show that the Ag NPs used here are very stable even when an eluent with a more positive zeta potential is used. The obtained results show better recovery rates, the same DLS diameters and only very few aggregates using the eluent water, which has a more positive zeta potential than $200 \mathrm{ppm} \mathrm{NaN}_{3}$.

The reproducibility was determined by repeated measurements. Ten runs with an overall absolute injection mass of 25.0 (membrane 1) and $312.6 \mathrm{ng}$ (membrane 2) of Ag NPs, each on a fresh membrane, were performed. Fig. 4 shows the fractograms obtained for membrane 2.

The fractograms of the ten runs performed on each of the two membranes 1 and 2 show a good reproducibility. Even though the zeta potential of the particles using the eluent water is considered to be less stable than the zeta potential using ultrapure water containing $200 \mathrm{mg} \mathrm{L}^{-1} \mathrm{NaN}_{3}$ as an eluent (see Table 2), higher recovery rates of over $87 \%$ were

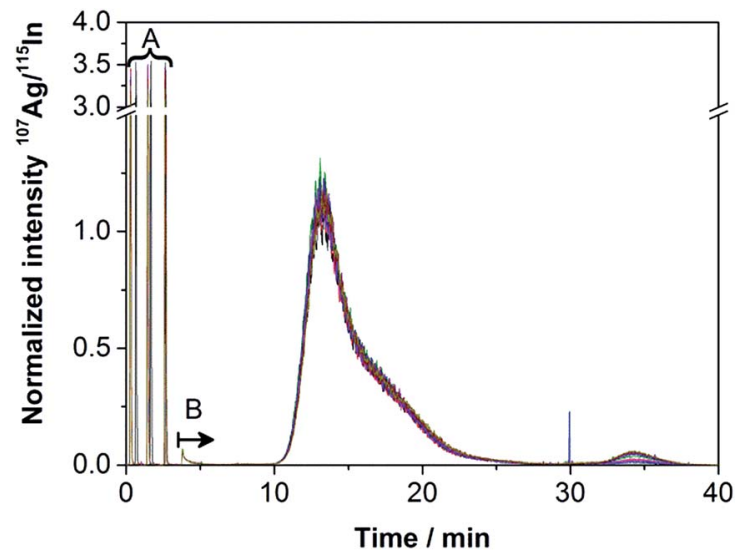

Fig. 4 Reproducibility of smoothed fractograms of Ag NPs (absolute mass of $31.3 \mathrm{ng} \mathrm{Ag}$ injected per run, membrane 2); (A) flow injection peaks between 0 and $3 \mathrm{~min}$ used for calibration, concentration $10 \mu \mathrm{g} \mathrm{L}^{-1}$, injected volume $11.53 \mu \mathrm{L}$; (B) AF4-elution start of the Ag NPs. obtained. An increase of the recovery rate has been detected from run 1 to 3 , stabilizing from run 3 on for membrane 2 . Membrane 1, onto which the lower concentration had been injected, showed constant recovery rates over all ten runs. In this work, we could not confirm that the membrane must generally be conditioned until the recovery rates do not increase further as shown before. ${ }^{26,29,30}$ This effect was only found for the slightly higher concentration of $31.3 \mathrm{ng}$ injected per run.

As illustrated in Fig. 4, the amount of potential sample loss through the void peak $(3.81 \pm 0.01 \mathrm{~min})$ and potential aggregates $(33.62 \pm 1.61 \mathrm{~min})$ was negligible. Slight differences between the membranes were observed concerning the resolution of the shoulder peak, retention time, recovery rate and LOD as Table 4 shows.

The recovery rates obtained by experiments without applied cross-flow and flow injection bridging the AF4 were $88.09 \pm$ $2.78 \%$ and $92.92 \pm 2.70 \%$, respectively. This indicates that the sample loss through the application of the cross-flow is insignificant in this case. A sample loss of $4.83 \% \mathrm{Ag}$ must occur in the AF4 system even when no separation force is applied.

\section{Quantification of the $\mathrm{Ag}$ residue on the membrane}

To determine the amount of $\mathrm{Ag}$ residue on the membrane, a calibration of the ICP-MS intensity was performed using seven $\mathrm{Ag}$ NP concentrations and an additional blank. These suspensions were pipetted $(0.5 \mu \mathrm{L})$, each in quintuplicates, on a fresh membrane and dried. The results of the measurements of the blank and six calibration droplets are shown in Fig. 5.

As expected, the blank droplet (at about $1.5 \mathrm{~mm}$ ) cannot be differentiated from the background. A linear calibration curve with a limit of detection of $4.2 \mathrm{pg}$ was obtained (see Fig. $\mathrm{S} 3 \dagger$ in the ESI). The first part of the membrane was completely ablated as Fig. 6 shows for the blank (Fig. 6a) and membrane 2 (Fig. 6b). A total Ag NP content of $312.6 \mathrm{ng}$ Ag has been injected over ten on-line AF4-ICP-MS runs on the membrane.

The highest intensities were found close to the sample injection point and on the channel edge. During the injection/ 
Table 4 Analytical figures of merit for the two membranes

\begin{tabular}{lllll}
\hline Membrane & $\begin{array}{l}\text { Total injected } \\
\text { amount of Ag/ng }\end{array}$ & $\begin{array}{l}\text { Retention time/ } \\
\min \end{array}$ & $\begin{array}{l}\text { Concentration/ } \\
\mathrm{mg} \mathrm{L}^{-1}\end{array}$ & $\begin{array}{l}\text { Recovery rate } \\
(\%)\end{array}$ \\
\hline 1 & 25.0 & $12.8 \pm 0.3$ & $56.19 \pm 1.07$ & $89.88 \pm 1.72$ \\
2 & 312.6 & $13.2 \pm 0.1$ & $54.40 \pm 2.63$ & $87.02 \pm 4.21$ \\
\hline
\end{tabular}

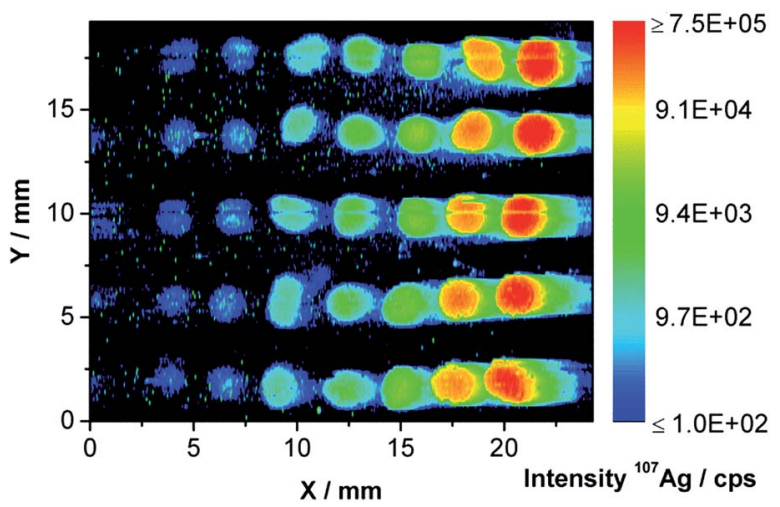

Fig. 5 LA-ICP-MS contour plot of ${ }^{107} \mathrm{Ag}$ for the calibration using a concentration series of the Ag NPs starting with a blank (left) and increasing concentrations to the right (logarithmic scale).

focusing step of the AF4 method, a tip flow of $0.2 \mathrm{~mL} \mathrm{~min}^{-1}$, a focus flow of $2.8 \mathrm{~mL} \mathrm{~min}^{-1}$ and a cross-flow of $2 \mathrm{~mL} \mathrm{~min}^{-1}$ were applied. The focus flow carries the NPs toward the channel top whereas the cross-flow pulls the particles close to the membrane resulting in the pattern illustrated in Fig. $6 \mathrm{~b}$.

After the blank correction, values of $1.10 \times 10^{-3} \mathrm{ng} \mathrm{Ag} \mathrm{mm}^{-2}$

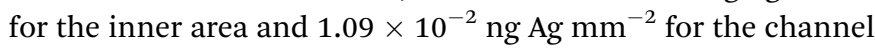
edge have been found. The total amount of $\mathrm{Ag}$ was found to be
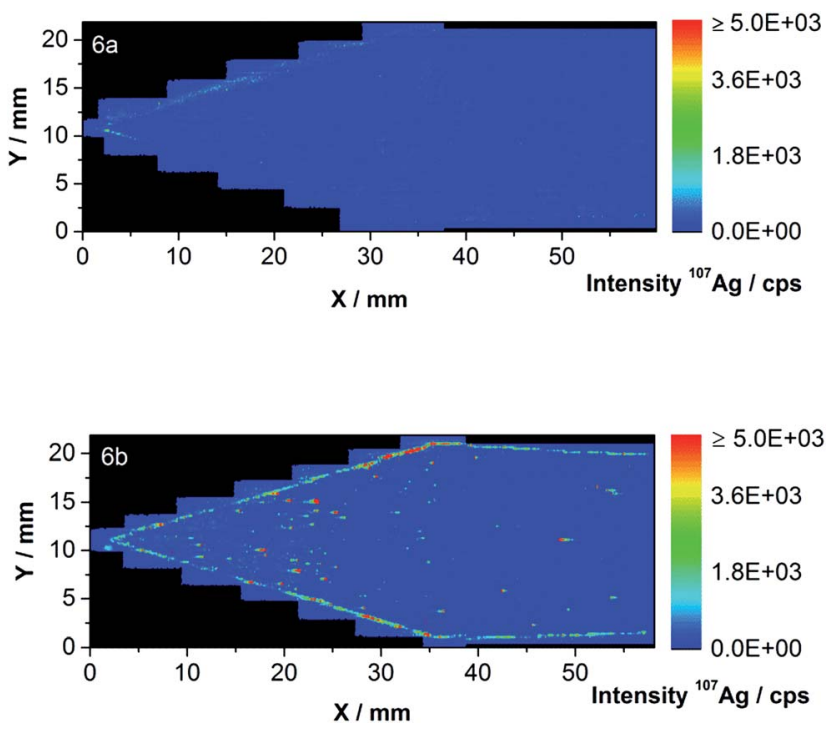

Fig. 6 ( $a$ and b) LA-ICP-MS contour plots of ${ }^{107} \mathrm{Ag}$ of the first part of the blank membrane (a) and membrane 2 (b) including the sample injection and focus point.
Table 5 Concentrations and recovery rates for an aqueous Ag standard solution of the four AF4 flows

\begin{tabular}{lrc}
\hline Flow & \multicolumn{1}{c}{${ }^{107} \mathrm{Ag} / \mathrm{ng} \mathrm{L}^{-1}$} & ${ }^{107} \mathrm{Ag}(\%)$ \\
\hline Detector flow & $190.13 \pm 6.79$ & $0.42 \pm 0.02$ \\
Cross-flow & $58.13 \pm 1.60$ & $0.33 \pm 0.01$ \\
Purge flow & $227.72 \pm 10.89$ & $0.32 \pm 0.02$ \\
Slot-outlet flow & $1121.04 \pm 19.05$ & $5.05 \pm 0.09$ \\
Total recovery rate & & $6.12 \pm 0.13$ \\
\hline
\end{tabular}

$1.81 \mathrm{ng}$ on the membrane part shown in Fig. 6b. This amount could be split into 0.71 and $1.10 \mathrm{ng} \mathrm{Ag}$ on the inner area and the channel edge, respectively. A total sample loss of $0.58 \% \mathrm{Ag}$ was therefore detected to occur in the first part of the ablated membrane.

In order to determine whether the deposition of silver on the membrane depends on the concentration of the sample, a membrane onto which a 12.5-fold lower total Ag mass of $25.0 \mathrm{ng}$ has been injected (10 runs) was ablated (membrane 1). The results showed 6.74- and 7.34-times lower amounts of $\mathrm{Ag}$ residue on the inner area and the channel edge, respectively (results not shown).

\section{Injection of an aqueous Ag standard solution}

Previous observations in our laboratory showed that ionic Ag, when not acidified, is not stable in solution and can interact with the used polyetheretherketone (PEEK) capillaries, vials and AF4 membranes. Therefore, the concentration of $\mathrm{Ag}$ ions in the $\mathrm{Ag}$ NP sample was determined by ultrafiltration. A concentration of $4.94 \pm 0.08 \mathrm{mg} \mathrm{L}^{-1}$ of $\mathrm{Ag}$, resulting in a recovery rate of $7.87 \pm$ $0.10 \%$, was found in the filtrate. Since the molecular weight of the $10 \mathrm{kDa}$ pores corresponds to a spherical diameter of $3.5 \mathrm{~nm},{ }^{39}$ it is assumed that the eluent contains only ionic Ag. Subsequently, $100 \mu \mathrm{L}$ of an aqueous $\mathrm{Ag}$ standard solution with a concentration of $10 \mathrm{mg} \mathrm{L}{ }^{-1}$ was injected into the $\mathrm{AF} 4$. The eluting sample flow, cross-flow, slot-outlet flow and purge flow were collected and analyzed. The determined concentrations and recovery rates are shown in Table 5 .

The analysis of the ionic Ag standard solution using off-line AF4-ICP-MS provides a combined recovery rate of $6.12 \pm 0.13 \%$. Over $93 \%$ of the ionic $\mathrm{Ag}$ is lost due to precipitation or adsorption caused by the lack of stabilizing ligands in the eluent. Losses could occur on both the vial walls and in the AF4 system.

As the ionic $\mathrm{Ag}$ concentration in the sample was found to be $7.87 \pm 0.10 \%$, dissolved $\mathrm{Ag}$ and dissolution of the nanoparticles could be an important source for low recovery rates. 


\section{Conclusions}

In this work, we have investigated recovery rates and possible sources of sample loss during AF4-ICP-MS experiments. For the first time LA-ICP-MS imaging of AF4 membranes was performed to identify the sources of sample loss. For a better comparability between the two completely ablated membrane pieces, the same channel areas for integration were chosen. Our work demonstrated that sample loss does occur on the AF4 membrane and is located close to the sample injection point and the channel edges. However, under optimized conditions interactions with the membrane are negligible. A concept of quantification of the $\mathrm{Ag}$ residue on the membrane using a matrix-matched dried droplet calibration was successfully applied for the LA-ICP-MS experiments. A correlation coefficient of $R^{2}=0.988$ was achieved for the calibration curve (see Fig. S3†). Nevertheless, a great challenge is still the internal standardization for LA-ICP-MS. During the LA-ICP-MS experiments performed in this work, no internal standard was used. Test measurements of the calibration droplets containing an aqueous Lu standard solution as a drift correction standard for both the laser and the ICP-MS showed deficient results. The ionic solution resulted in much larger droplet sizes than the NPs. As comparable homogeneities and a similar behavior on the membrane surface could not be assured, this procedure was not applicable. Other experiments of mixing an ionic internal standard into the AF4 eluent also resulted in irregularities. A method for internal standardization is therefore still lacking but needs to be developed for future experiments.

Analyses also showed that losses through the cross-flow do not have a great impact on the recovery rates for the conditions employed here. The greatest amount of sample loss was found to be due to insufficiently stabilized ionic Ag present in the sample. It is therefore essential to determine its amount and avoid Ag NP dissolution.

Recovery rates and sample loss strongly depend on the system analyzed and the conditions chosen. As only one Ag NP system under specific conditions has been investigated so far, future studies are necessary to understand sample loss completely. However, after optimization recovery rates of about $90 \%$ were achieved. The results show that AF4-ICP-MS is an excellent technique for the analysis of Ag NPs. Future studies investigating their environmental behavior applying the gained knowledge are planned.

\section{Acknowledgements}

The research leading to these results has received partial funding from the European Union Seventh Framework Programme (FP7/2007-2013) under grant agreement no. 263147 (NanoValid - Development of reference methods for hazard identification, risk assessment and LCA of engineered nanomaterials).

\section{Notes and references}

1 D. R. Monteiro, L. F. Gorup, A. S. Takamiya, A. C. Ruvollo, E. R. Camargo and D. B. Barbosa, Int. J. Antimicrob. Agents, 2009, 34, 103-110.
2 R. Kaegi, B. Sinnet, S. Zuleeg, H. Hagendorfer, E. Mueller, R. Vonbank, M. Boller and M. Burkhardt, Environ. Pollut, 2010, 158, 2900-2905.

3 F. Gottschalk and B. Nowack, J. Environ. Monit., 2011, 13, 1145-1155.

4 H. Goenaga-Infante and E. H. Larsen, Anal. Bioanal. Chem., 2014, 406, 3831-3833.

5 A. B. Smetana, K. J. Klabunde, G. R. Marchin and C. M. Sorensen, Langmuir, 2008, 24, 7457-7464.

6 E. T. Hwang, J. H. Lee, Y. J. Chae, Y. S. Kim, B. C. Kim, B. I. Sang and M. B. Gu, Small, 2008, 4, 746-750.

7 E. Navarro, F. Piccapietra, B. Wagner, F. Marconi, R. Kaegi, N. Odzak, L. Sigg and R. Behra, Environ. Sci. Technol., 2008, 42, 8959-8964.

8 J. Y. Liu and R. H. Hurt, Environ. Sci. Technol., 2010, 44, 21692175.

9 J. S. Kim, E. Kuk, K. N. Yu, J. H. Kim, S. J. Park, H. J. Lee, S. H. Kim, Y. K. Park, Y. H. Park, C. Y. Hwang, Y. K. Kim, Y. S. Lee, D. H. Jeong and M. H. Cho, Nanomedicine, 2007, 3, 95-101.

10 M. J. Hajipour, K. M. Fromm, A. A. Ashkarran, D. J. de Aberasturi, I. R. de Larramendi, T. Rojo, V. Serpooshan, W. J. Parak and M. Mahmoudi, Trends Biotechnol., 2012, 30, 499-511.

11 O. Choi, K. K. Deng, N. J. Kim, L. Ross, R. Y. Surampalli and Z. Q. Hu, Water Res., 2008, 42, 3066-3074.

12 M. Hassellöv, J. W. Readman, J. F. Ranville and K. Tiede, Ecotoxicology, 2008, 17, 344-361.

13 A. Lopez-Serrano, R. M. Olivas, J. S. Landaluze and C. Camara, Anal. Methods, 2014, 6, 38-56.

14 K. Tiede, A. B. A. Boxall, S. P. Tear, J. Lewis, H. David and M. Hassellöv, Food Addit. Contam., Part A, 2008, 25, 795-821.

15 K. Tiede, S. P. Tear, H. David and A. B. A. Boxall, Water Res., 2009, 43, 3335-3343.

16 S. Pabisch, B. Feichtenschlager, G. Kickelbick and H. Peterlik, Chem. Phys. Lett., 2012, 521, 91-97.

17 D. M. Mitrano, A. Barber, A. Bednar, P. Westerhoff, C. P. Higgins and J. F. Ranville, J. Anal. At. Spectrom., 2012, 27, 1131-1142.

18 F. Laborda, S. Ruiz-Begueria, E. Bolea and J. R. Castillo, J. Chromatogr. A, 2011, 1218, 4199-4205.

19 E. P. Gray, T. A. Bruton, C. P. Higgins, R. U. Halden, P. Westerhoff and J. F. Ranville, J. Anal. At. Spectrom., 2012, 27, 1532-1539.

20 B. Meermann, A. L. Fabricius, L. Duester, F. Vanhaecke and T. Ternes, J. Anal. At. Spectrom., 2014, 29, 287-296.

21 H. Hagendorfer, R. Kaegi, J. Traber, S. F. L. Mertens, R. Scherrers, C. Ludwig and A. Ulrich, Anal. Chim. Acta, 2011, 706, 367-378.

22 B. Schmidt, K. Loeschner, N. Hadrup, A. Mortensen, J. J. Sloth, C. B. Koch and E. H. Larsen, Anal. Chem., 2011, 83, 2461-2468.

23 M. Baalousha, B. Stolpe and J. R. Lead, J. Chromatogr. A, 2011, 1218, 4078-4103.

24 E. Bolea, J. Jimenez-Lamana, F. Laborda and J. R. Castillo, Anal. Bioanal. Chem., 2011, 401, 2723-2732. 
25 S. Dubascoux, F. von der Kammer, I. Le Hecho, M. P. Gautier and G. Lespes, J. Chromatogr. A, 2008, 1206, 160-165.

26 K. Loeschner, J. Navratilova, S. Legros, S. Wagner, R. Grombe, J. Snell, F. von der Kammer and E. H. Larsen, J. Chromatogr. A, 2013, 1272, 116-125.

27 J. Gigault, T. J. Cho, R. I. MacCuspie and V. A. Hackley, Anal. Bioanal. Chem., 2013, 405, 1191-1202.

28 N. Bendixen, S. Losert, C. Adlhart, M. Lattuada and A. Ulrich, J. Chromatogr. A, 2014, 1334, 92-100.

29 A. Ulrich, S. Losert, N. Bendixen, A. Al-Kattan, H. Hagendorfer, B. Nowack, C. Adlhart, J. Ebert, M. Lattuada and K. Hungerbühler, J. Anal. At. Spectrom., 2012, 27, 1120-1130.

30 S. A. Cumberland and J. R. Lead, J. Chromatogr. A, 2009, 1216, 9099-9105.

31 BAM Federal Institute for Materials Research and Testing, Certified Reference Material BAM-N001, Particle Size Parameters of Nano Silver, Berlin, Germany, 2013.

32 E. Moreno-Gordaliza, D. Esteban-Fernandez, C. Giesen, K. Lehmann, A. Lazaro, A. Tejedor, C. Scheler, B. Canas,
N. Jakubowski, M. W. Linscheid and M. M. Gomez-Gomez, J. Anal. At. Spectrom., 2012, 27, 1474-1483.

33 A.-L. Fabricius, L. Duester, B. Meermann and T. Ternes, Anal. Bioanal. Chem., 2014, 406, 467-479.

34 H. Prestel, R. Niessner and U. Panne, Anal. Chem., 2006, 78, 6664-6669.

35 L. L. Schramm, Emulsions, Foams, Suspensions, and Aerosols: Microscience and Applications, Wiley, Weinheim, Germany, 2nd edn, 2014, vol. 1, ch. 5.3.2, p. 175.

36 A. R. Poda, A. J. Bednar, A. J. Kennedy, A. Harmon, M. Hull, D. M. Mitrano, J. F. Ranville and J. Steevens, J. Chromatogr. A, 2011, 1218, 4219-4225.

37 J. C. Giddings, in Field-Flow Fractionation Handbook, ed. M. Schimpf, K. Caldwell and J. C. Giddings, Wiley, New York, 1st edn, 2000, vol. 1, ch. 1, p. 12.

38 R. N. Qureshi and W. T. Kok, LC GC Eur., 2010, 23, 18-25. 39 L. R. Snyder, J. J. Kirkland and J. W. Dolan, Introduction to Modern Liquid Chromatography, Wiley, Hoboken, New Jersey, 3rd edn, 2010, vol. 1, ch. 13.3.1.1, p. 580. 